come, Thomas Carlyle, who was unable to hold a pen for the last fifteen years of his life, would have given to $\mathrm{Mr}$. Julius Wolff! We are not told, however, of any case in which the treatment has proved efficacious in old age. The method, at present, is comparatively in its infancy."

It is a somewhat curious coincidence that, about six or geven months ago, I suggested systematic massage as a remedy for "writer's camp" in two cases-one that of a lady, and the other that of a gentleman. In the first case, Captain B. told me that he had a relative who was suffering from the affection, and that he "would give anything if she could be cured." I asked him to send her to Sir Joseph Fayrer, and told him I would write to that gentleman, suggesting the systematic application of massage. I did write, but have heard nothing of the case since. In the other case, I suggested this mode of treatment to Col. C. G.. but I don't think he ever tried it. I have, however, sent him the above extract, and trust he may be induced now to give the treatment a fair trial.

\section{VINCENT RICHARDS.}

Goalundo, March, 1885

\section{MESS SUBSCRIPTIONS.}

TO The Editor of "The Pioneer."

SrR,-With your permission, I should like to ventilate the subject of Medical Officers' mess subscriptions in Native Corps, with a view to ascertaining the feelings of those concerned. Under a recent ruling, mess entertainments are to be paid for according to staff corps pay, all extra allowances being excluded. For instance, should the Medical Officer be over twenty years' service, he will pay on Rs. 852-3-7, his emoluments all told being Rs. 1,000; whilst the Commanding Officer will pay on Rs. 827-14, although he draws Rs. 1,427-14 per mensem! In such an instance the Medical Officer will have the honour and glory of paying more for the entertainment of mess guests than the Commanding Officer, who receives at least Rs. 400 odd more pay. The injustice of this rule will be severely felt by many. While on this subject, I may mention another. It is the custom, in all matters relating to a mess, to enter the Medical Officer's name, no matter what is his seniority, last, even after the last joined lieutenant. Now, I presume there are few medical men with so small a mind as to regard this slight-for slight it is-other than as a matter of very small importance; but this sort of treatment lowers him in the eyes of the natives. In mess matters the Medical Officer's name should, undoubtedly, be entered according to his seniority. As affairs now stand, many a Medical Officer will find his name at the bottom of the list, and opposite it a sum to be deducted for the entertainment of guests invited in the name of the Commanding Officer and Officers greater than that to be paid by the Commandant himself !

I am, \&c., I. M. S.

\section{ASSISTAN I SURGEONS' PROMOTION EXAMINATION.}

THr following questions were set at the recent Examination of Assistant Surgeons in Bengal for promotion to the superior grades in accordance with para. 6, Chapter $\mathrm{XL}$, of the Bengal Medical liegulations of 1851 :

\section{Medicine and Therapeutics.}

I. Give the course, symptoms, complications, and treatment of Bright's disease.

II. Detail the pathology, course, and various terminations of diabetes mellitus. Prescribe for it and its complications, and arrange its dietetics.

III. Contrast a case of true remittent fever with one of enteric throughout their course. Mlention the differences in their lines of treatment.

IV. Treat a case of cancrum oris, locally and generally, and give the actions of the remedies employed.

\section{Midwifery.}

1. You are sent for to a case, and find that labour began 24 hours before your arrival. Os dilated to the size of three inches, membranes ruptured 12 hours. Head presenting, but not engaged in the brim. What would you do?

2. How would you distinguish a breach from a shoulder presentation?

3. Give the treatment of post-partum hæmorrhage.

4. Wbat is meant by missed abortion, and how would yon diagnose the condition?

5. Describe a case and indicate the treatment of trismus infantum.

6. What are the distinctive symptoms of rickets?

$N$. B.-No. 1, two of the next three, and one of the last two questions to be answered.

\section{Surgery.}

1. What do you mean by meningocele? Enumerate the methods of treating this disease, and state which of these methods has been attended with most success.

2. Under what conditions has excision of the rectum been performed? Describe the operation.

3. Give an account of the operation commonly called Cock's for opening the urethra through the perineum. Under what circunstances would you adopt this operation?

4. Tracheotomy is often performed for the relief of srmptoms due to œdema of the glottis. After such an operation what conditions would guide you in removing or retaining the tracheotomy tube?

\section{Medical Jurisprudence.}

1. What appearances would make you infer that a wound had been inflicted before cleath, and what appearances would point to its having been caused after death ?

2. How would you treat a case of acute arsenic prisoning? What post-mortem appearances would you expect to find on the body of a person who died from acute arsenic poisoning ?

3. What are the various forms of death from hanging? Which is the most common form of death in this country; and what are the post-mort em appearances of this form of death?

4. Describe in detail how the seeds of the abrus precatorius are used in this country by professional poisoners. What are the symptoms of poisoning with the seeds of abrus precatorius; and what post-mortem appearances would you expect to find in a case of death from poisoning with these seeds?

5. What post-mortem appearances would point to an infant having been born dead; and what appearances to the child having been born alive?

$N$. B.-Any three of these questions, but not more than three, to be answered.

\section{甘ital statistiqs.}

\section{HEALTH OF CALCUTTA.}

THF total number of deaths, registered during the week ending 14th February, was 290 against 273 and 272 in the two preceding weeks, and 36 in excess of the corresponding week last year. Under the head of cholera, there were 51 deaths against 30 and 17 in the two preceding weeks, the quinquennial mean of the week being 20. The rapid rise in cholera mortality was probably due to the late light rains, which had the effect of moistening the surface without scouring it, thereby helping changes of decomposition in filthy localities. The incidence of the disease was sporadic. From smail-pox 7 deaths were registered against a quinquennial mean of 6 . Fevers and bowel-complaints were slightly in excess of the averages. There were 19 deaths from diarrhœa, and 16 from drsentery. The general mortality was at the rate of $34 \cdot 9$ per 1000 per annum.

During the week ending 21 st February, the number of deaths registered was 260 , being 38 in excess of the corresponding week - last year. Under the head of cholera, 30 deaths were registered, the quinquennial mean of the week being 32 . From small-pox there were 6 deaths, the quinquennial mean of the week being 4 . Fevers and bowel-complaints continue to be slightly in excess of the averages. The general mortality was at the rate of 31.3 per 1000 per anuum.

During the week ending 28th February, the number of deaths reyistered was 260 , being 36 in excess of the corresponding week last year. Under the head of cholera, 39 deaths were registered, the quinquennial mean of the week being 34 . There were 11 deaths from small-pox against 6 and 7 in the two preceding weeks, the quinquennial mean being 8 . The deaths from fevers and bowelcomplaints continue to be somewhat in excess of the averagres. The general mortality of the week was at the rate of $31 \cdot 3$ per 1000 per annum. 
For the month of January, the Health Officer, Dr. O'Brien, reports as follows :-

Births. - The number of births registered in January was 735 against 798 in the preceding month, giving an annual ratio of $20 \cdot 3$ against $22 \cdot 1$ per 1,000 of population. The number exceeds all the corresponding figures of the past decade, and also surpasses the mean of the decennium by 159 . The excess of 30 births over those of the corresponding month of the previous vear is shared by all classes of the community except other classes. There were 389 inale and 346 female births registered in the month. The mean of the past decade was 576 .

Vaccination.-There were 1,866 cases of vaccination and 446 cases of re-vaccination in the month under review against 1,401 and 361, respectivels, in the preceding month. Of the primary vaccinations, 699 were under one rear, 1,004 above one year and under six years, and 163 above six years. Of the 1,866 cases, 1,825 or $97 \cdot 7$ per cent. were successful ; and 41 or $2 \cdot 2$ per cent. were doubtful, or could not be traced. There were 1,027 males and 839 females vaccinated during the month. Among the different races, 1,266 were Hindus, 401 Mohamedans, 122 Mixed races, 40 Non-Asiatics, and 37 were other classes.

Mortality.-There were 1,230 deaths, exclusive of still births, registered in January against 1,273 in the preceding month, giving an annual ratio of 34 against $35 \cdot 2$ per 1,000 of population. The proportion of male to female deaths was as 117 to 100 . The monthly total was less than 4 corresponding figures of the past decade, and falls short of the decennial mean by 11 . The excess of 207 anths over those of the corresponding month of the previous year is due to the increase of deaths from all the principal diseases, and is shared by all races excepting Non-Asiatics and other classes. There were 79 deaths from cholera against 78 in the preceding month. The number is less than 5 corresponding figures of the past decade, and is also less than the decennial mean by 31 . From sinall-pox, 17 deaths were registered against 9 in the preceding month. The number is less than the mean of the past decale by 5 . The deaths from fevers amounted to 394 against 399 in the preceding month. The number is less than 5 corresponding figures of the past decade, and falls short of the mean of the decennium by 29 . There were 209 deaths from bowel-complaints against 208 in the preceding month. The number is less than four corresponding figures of the past decade. The mortality from other cause. :imounted to 512 against 559 in the preceding month. The total exceeds all the corresponding figures of the past decade, excepting 1878,1881 and 1883 , and surpasses the decennial mean by 38 . With regard to the local distribution of diseases, the following sections show the highest death-rates, viz., Hastings $58 \cdot 2$, Taltolla $47 \cdot 4$, Jorasanko $45 \cdot 7$, and Shampoker $42 \cdot 3$. The following sections show death-rates below the average, viz., Comertolly $21 \cdot 9$, Waterlon Street $24 \cdot 8$, and Park Street $26 \cdot 5$.

Infant mortality reckoned on estimated births was 324.7 against 994.2 per 1,000 of population per annum in the preceding month. 294 per 1 different races the ratios were as follows, viz.:-Hindus 315 , Mahomedans $410^{\circ} 3$, and Christians $135^{\circ} 6$. There was no infant death among other classes in the month under record.

\section{HEALTH OF MADRAS.}

During the week ending 6 th February, 398 persons died in the City of Madras, giving a death-rate of 51.8 per mille per annum against $44 \cdot 7$ as the mean for the corresponding week of the ten previous years. There were 15 deaths from cholera, 23 from diarrhoa 62 from dysentery, and 86 from fever. In the week ending 13 th February, 330 persons died, giving a rate of $43 \cdot 0$ against 46.1 for the ten previous years. There were 19 deaths from cholera, 23 from diarrhœa, 56 from dysentery and 78 from fever. In the week ending 20 th February, 293 persons died, giving a rate of 38.1 a ainst 44.0 for the ten previous years. There were 5 deaths from cholera, 30 from diarrhoa, 38 from dysentery and 89 from fever. In the week ending 27 th February. 316 persons died, giving a rate of $41 \cdot 2$ against $45 \cdot 2$ for the ten previous years. There were 12 deaths from cholera, 19 from diarrhœa, 41 from dysentery and 83 from fever.

\section{HEALTH OF BOMBAY.}

Is the week ending 24th February, 45 deaths from cholera were recistered it lomb compared with 9 in the previous week. The majority of the persons attacked in Bombay were pilgrims from Nassick, where there has been a very extensive outbreak of the disease. A temporary cholera hospital was opened at Arthurroad, and pilgrims returning to Gujerat were being induced not to enter the city, but to join the Baroda line at Dadur junction. In the week ending 3rd March, the mortality from cholera was 43, and in the two following weeks, 34 and 49 repectively.

At Nassick, an outbreak of cholera began amongst pilgrims on the 5th February, and was at its worst from the 14th to the 19th, when $\overline{5} 7$ persons died out of 98 attacked, the highest number of deaths on one day (the 17th) being 13. The disease then begall to decline, and from the 20th to the 27th there were 23 deaths to 36 attacks. From the 1 st to the 3rd there were 2 dearhs to 3 attacks. At Trimbak, 45 deaths occurred in February ; but now, as in Nassick, the reports are more satisfactory. The district is fairly free, though there have a few cases occurred here and there in Niphad, Igatpuri, Dindori, Malegaon and Nasik Talukas amongst the pilgrims touching at these places on their way home.

\section{HEALTH OF PUNJAB IN 1883.}

The year, we are told, was an unusually healthy one, and the number of deaths from fever and bowel-complaints were less than in any of the five preceding years. The death-rate throughout the province was 39 per 1,000 , ranging from 53.32 in the Sialkot district to 10.01 at Simla. The next healthier districts to Simla were Kohat, Dera Ghazi Khan, and Peshawar; and this has been the case for the last two years, although Peshawar has the reputation of being a very unhealthy station. There was onls one epidemic outtreak of cholera, which took place in the Delhi division; but small-pox prevailed to a considerable extent in eleven districts, and the number of deaths was larger than in any of the three preceding years. The expenditure on sanitary works is steadily increasing in many of the towns, which the Sanitary Commissioner regards as a proof that the Municipalities are taking more interest in such matters than in former years; and the attention of the district officers is specially directed to the encourarement of village sanitation. As regards the drainage of the principal towns, great improvements were made in the city of Lahor, and a scheme was prepared for improving the drainage of Anarkali. Plans for the drainage of Sialkot city were also prepared, and at Amritsar good progress was made with the extra-mural drainare, but very little was done towards the drainase of the city itself. It is somewhat surprising that the Municipalities do not pay more attention to the removal and disposal of refuse and manure; for in some towns a considerable income is realised from this source. Thus, Amritsar derives Rs. 25,000 from the sale of its refuse, and Ludiana Rs. 8,000. But in most of the other towns little was done in this direction. In Lahore the new reservoir was nearly completed; it has since been finished, and the system of water supply has worked satisfactorily. In Amritsar the plans for water-supply were well advanced; at Simla, the new reservoir was about half completed; while covered drinking tanks were finished at Deoband and on the Marri and Abbottabad road.

Comparative Mortality in Cities of North-Western Pro. vinces, and Punjab having more than 50,000 inhıbitants.

NORTH-WESTERN PROVINCES (NOVEMBER; 1884).

\begin{tabular}{|c|c|c|c|c|c|c|}
\hline City of Municipality. & 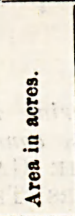 & 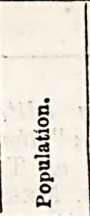 & 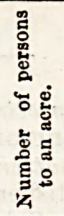 & 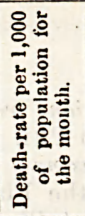 & 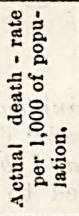 & 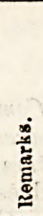 \\
\hline 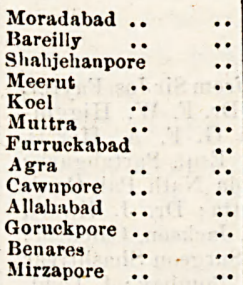 & $\begin{array}{r}1,650 \\
2,785 \\
5,625 \\
401 \\
400 \\
1,146 \\
2,551 \\
14,425 \\
2,389 \\
19.747 \\
2,920 \\
3,141 \\
3,376\end{array}$ & \begin{tabular}{|r|}
67,387 \\
103,100 \\
77404 \\
60,948 \\
62,443 \\
55,016 \\
74,872 \\
138,094 \\
120,161 \\
150,338 \\
57,922 \\
208,083 \\
85,362
\end{tabular} & $\begin{array}{r}40 \\
37 \\
13 \\
151 \\
159 \\
48 \\
29 \\
9 \\
50 \\
7 \\
19 \\
66 \\
25\end{array}$ & $\begin{array}{r}5 \cdot 56 \\
5 \cdot 41 \\
3 \cdot 27 \\
4 \cdot 51 \\
11 \cdot 00 \\
8 \cdot 37 \\
2 \cdot 91 \\
3 \cdot 39 \\
2 \cdot 91 \\
1 \cdot 24 \\
1.59 \\
2 \cdot 01 \\
1 \cdot 51\end{array}$ & $\begin{array}{r}6672 \\
64 \cdot 92 \\
39 \cdot 24 \\
54 \cdot 12 \\
132 \cdot 00 \\
100 \cdot 44 \\
34 \cdot 92 \\
40 \cdot 68 \\
31 \cdot 92 \\
14 \cdot 38 \\
19 \cdot 08 \\
24 \cdot 12 \\
18 \cdot 12\end{array}$ & \\
\hline
\end{tabular}

PUNJAB (FroM 19TH Ocrober to 22ND NOVEMBER, 1884).

\begin{tabular}{|c|c|c|c|c|c|c|c|}
\hline $\begin{array}{l}\text { Delhi } \\
\text { Umritsur } \\
\text { Lahore } \\
\text { Peshawur }\end{array}$ & $\begin{array}{l}\ddot{y} \\
\ddot{a}\end{array}$ & $\begin{array}{l}\ddot{0} \\
\ddot{0} \\
\ddot{*}\end{array}$ & $\begin{array}{r}1,437 \\
807 \\
461 \\
500\end{array}$ & $\begin{array}{r}173,393 \\
151,896 \\
149,369 \\
79,982\end{array}$ & $\begin{array}{r}120 \\
188 \\
324 \\
159\end{array}$ & $\begin{array}{l}3 \cdot 8 \\
38 \\
24 \\
1 \cdot 5\end{array}$ & $\begin{array}{l}45 \cdot 6 \\
45 \cdot 6 \\
28 \cdot 8 \\
18 \cdot 0\end{array}$ \\
\hline
\end{tabular}

\section{gitledial gews.}

MAdRAS UNIVERSiTY. - At the convocation of Madras University held on the 18th ultimo, one degree of M.D.. one of M.B. and C.M., and four Licenciatships in Medicine and Surgery were conferred. 